\title{
Fetal endocrine responses to prolonged reduced uterine blood flow are altered following bilateral sectioning of the carotid sinus and vagus nerves
}

\author{
P E Stein, S E White, J Homan, L Fraher, H H G McGarrigle', \\ $M$ A Hanson ${ }^{1}$ and A D Bocking
}

Departments of Physiology, Obstetrics and Gynaecology and Biochemistry, MRC Group in Fetal and Neonatal Health and Development, Lawson Research Institute, University of Western Ontario, London, Canada and ${ }^{1}$ Departments of Physiology and Obstetrics and Gynaecology, University College, London, UK (Requests for offprints should be addressed to A D Bocking, Lawson Research Institute, St Joseph's Health Centre, 268 Grosvenor Street, London, Ontario, Canada N6A 4V2)

\begin{abstract}
The present study examines the effect of carotid sinus/ vagosympathetic denervation on fetal endocrine responses to prolonged reduced uterine blood flow (RUBF). Fetal sheep had vascular catheters inserted following bilateral sectioning of the carotid sinus and vagus nerves (denervated, $n=7$ ) or sham denervation (intact, $n=7$ ). Uterine blood flow was mechanically restricted at $126 \cdot 1 \pm 0 \cdot 7$ days (mean \pm s.E.M.) for $24 \mathrm{~h}$, decreasing arterial oxygen saturation by $47 \cdot 3 \pm 2 \cdot 6 \%(P<0 \cdot 01)$. Fetal plasma samples were obtained at $-1,3,6,12$ and $24 \mathrm{~h}$ for subsequent analyses of arginine vasopressin (AVP), angiotensin II and catecholamines. The AVP response to prolonged RUBF was markedly attenuated in denervated fetuses $(15 \cdot 6 \pm 3 \cdot 6$ to $34.9 \pm 6.0 \mathrm{pg} / \mathrm{ml})$ when compared with intact $(10 \cdot 0 \pm 1 \cdot 4$ to $127 \cdot 3 \pm 28 \cdot 4 \mathrm{pg} / \mathrm{ml})$. In contrast, intact
\end{abstract}

fetuses demonstrated no change in plasma angiotensin II concentrations with RUBF whereas denervated fetuses demonstrated a marked increase from $47.5 \pm 18.9$ to $128 \cdot 7 \pm 34 \cdot 2 \mathrm{pg} / \mathrm{ml}$. The norepinephrine and epinephrine responses to prolonged RUBF were attenuated in denervated fetuses $(950 \cdot 1 \pm 308 \cdot 9$ and $155 \cdot 8 \pm 58 \cdot 5$ to $1268 \cdot 3 \pm 474 \cdot 6$ and $290 \cdot 6 \pm 160 \cdot 2 \mathrm{pg} / \mathrm{ml}$ respectively) when compared with intact $(1558 \cdot 3 \pm 384 \cdot 4$ and $547 \cdot 3 \pm 304 \cdot 7 \mathrm{pg} / \mathrm{ml}$ to $3289 \cdot 2 \pm 1219 \cdot 8$ and $896 \cdot 8 \pm$ $467 \cdot 8 \mathrm{pg} / \mathrm{ml}$ respectively). These results support a role for the peripheral chemoreceptors in mediating fetal endocrine responses to prolonged RUBF, which may in part lead to the altered cardiovascular responses observed in denervated fetuses under these conditions.

Journal of Endocrinology (1998) 157, 149-155

\section{Introduction}

Under conditions of acute hypoxia in sheep, fetal plasma arginine vasopressin (AVP) (Rurak 1978, Daniel et al. 1983), angiotensin II (Broughton Pipkin et al. 1974) and catecholamine (Jones \& Robinson 1975, Gu et al. 1985) concentrations increase. The role of the peripheral chemoreceptors in mediating these responses remains controversial. Sectioning of the cervical vagosympathetic trunk attenuates the rise in plasma AVP concentrations (Rurak 1978) whereas sinoaortic (Raff et al. 1991) or carotid sinus denervation (Giussani et al. 1994) does not. Furthermore, sinoaortic denervation attenuates the rise in plasma angiotensin II concentrations (Wood et al. 1990) whereas carotid sinus denervation does not (Green et al. 1997). The role of the peripheral chemoreceptors in mediating the rise in plasma catecholamine concentrations during acute hypoxia has not been examined, although Jensen \& Hanson (1995) have reported an attenuation of the catecholamine response to acute fetal asphyxia following carotid sinus denervation.

When hypoxia is maintained, plasma AVP concentrations return to normoxic values after $12 \mathrm{~h}$ whereas plasma catecholamine concentrations remain elevated (Hooper et al. 1990). The fetal angiotensin II response to prolonged hypoxia has not been characterized. The role of the peripheral chemoreceptors in mediating fetal endocrine responses to prolonged hypoxia has also not been studied. Furthermore, the contribution of fetal endocrine responses to the sustained tachycardia and transient rise in arterial blood pressure observed during prolonged hypoxia is not known (Bocking et al. 1988). Recent studies in our laboratory, however, suggest a role for the peripheral chemoreceptors in mediating these cardiovascular alterations during prolonged reduced uterine blood flow (RUBF) (Stein et al. 1997).

These studies were designed to test the hypothesis that fetal endocrine responses to prolonged hypoxia are mediated in part by peripheral chemoreceptor function. 
Fetal plasma AVP, angiotensin II and catecholamine concentrations were therefore measured before and during prolonged fetal hypoxia, secondary to RUBF, in intact and carotid sinus/vagosympathetic denervated fetal sheep.

\section{Materials and Methods}

\section{Surgical procedures}

Surgery was performed on 14 pregnant sheep of known mating dates between 118 and 126 days gestation under general anesthesia (intravenous thiopental sodium for induction; $1 \cdot 0-1 \cdot 5 \%$ halothane in oxygen for maintenance). A polyvinyl catheter was placed in a maternal femoral vein (V11; Bolab, Lake Havasu City, AZ, USA) followed by a vascular clamp around the maternal common internal iliac artery. Carotid sinus denervation was performed bilaterally in seven fetuses followed by bilateral mid-cervical vagotomy; these were termed 'denervated' fetuses. In seven fetuses serving as controls, these nerves were identified and left uncut; these were termed 'intact' fetuses. Catheters were placed in the fetal carotid and brachiocephalic arteries, jugular vein, trachea (V4; Bolab) and amniotic cavity (V11; Bolab). A transit-time flow transducer (Transonic Inc, Ithaca, NY, USA) was placed around the contralateral carotid artery. All cables, catheters and electrodes were exteriorized through the maternal flank. Animals were housed in individual cages with free access to food and water, and allowed 4 days to recover from surgery before experiments were commenced. All animals were treated in compliance with guidelines established by the Canadian Council on Animal Care and according to protocols approved by the Animal Care Committees of the Lawson Research Institute and the University of Western Ontario.

\section{Experimental protocol}

All experiments began between 0900 and $1000 \mathrm{~h}$ with a $2 \mathrm{~h}$ control period. At time 0, the vascular clamp was adjusted such that uterine blood flow was reduced sufficiently to decrease fetal arterial oxygen saturation $\left(\mathrm{SaO}_{2}\right)$ by approximately $50 \%$. Fetal arterial blood samples $(0 \cdot 2 \mathrm{ml})$ were drawn at $-5,5,10$ and $15 \mathrm{~min}$ and $1,2,3$, $6,12,16,20$ and $24 \mathrm{~h}$ to ensure a stable reduction in fetal $\mathrm{SaO}_{2}$. Blood gases and $\mathrm{pH}$ were determined at these time intervals using an ABL blood gas analyzer (Radiometer, Copenhagen, Denmark). Additional arterial blood samples $(3.0 \mathrm{ml})$ were drawn at $-1,3,6,12$ and $24 \mathrm{~h}$ for subsequent measurement of plasma AVP, angiotensin II and catecholamine concentrations. Fetal blood samples $(2.0 \mathrm{ml})$ used for the determination of plasma AVP and angiotensin II concentrations were transferred to glass tubes whereas blood samples $(1.0 \mathrm{ml})$ used for the determination of plasma catecholamine concentrations were immediately transferred to glass tubes containing sodium metabisulphite/EDTA. All tubes were centrifuged at $2800 \mathrm{~g}$ for $5 \mathrm{~min}$ at $4{ }^{\circ} \mathrm{C}$. Plasma was then removed and stored at $-80{ }^{\circ} \mathrm{C}$ for subsequent analyses.

\section{Plasma AVP concentrations}

Plasma AVP concentrations were measured as previously described (Giussani et al. 1996) after chromatographic separation using a double-antibody RIA with reagents purchased as a kit (Mitsubishi Yuka, Mitsubishi Petrochemical Co. Ltd, Japan, distributed in the UK by IDS Ltd, Boldon, Tyne and Wear, UK). SepPak $\mathrm{C}_{18}$ cartridges (Waters Associates, Milford, MA, USA) were mounted on a Super Separator-24 manifold and washed with $10 \mathrm{ml}$ volumes of methanol and distilled water. Plasma samples $(0.5 \mathrm{ml})$ were mixed with equal volumes of $0.1 \mathrm{M} \mathrm{HCl}$ and applied to columns. Columns were washed with $10.0 \mathrm{ml} \mathrm{4 \%}$ acetic acid, and AVP was eluted with $2.5 \mathrm{ml}$ methanol. Extracts were dried at $37{ }^{\circ} \mathrm{C}$ with a jet of air, and residues were reconstituted in $1.0 \mathrm{ml}$ phosphate buffer. Duplicate aliquots (volume dependent on expected AVP concentration) were adjusted to $0.3 \mathrm{ml}$ with phosphate buffer, and AVP antiserum was added $(0 \cdot 1 \mathrm{ml})$. Samples were mixed and incubated at $4{ }^{\circ} \mathrm{C}$ for $20 \mathrm{~h}$. Then $0 \cdot 1 \mathrm{ml}{ }^{125} \mathrm{I}-\mathrm{AVP}$ was added, and tubes were incubated at $4{ }^{\circ} \mathrm{C}$ for an additional $20 \mathrm{~h}$. A second antibody $(0.1 \mathrm{ml})$ and polyethylene glycol $(0.4 \mathrm{ml})$ were added, and samples incubated at $4{ }^{\circ} \mathrm{C}$ for $4 \mathrm{~h}$. Samples were centrifuged $(2000 \mathrm{~g})$ at $4{ }^{\circ} \mathrm{C}$ for $30 \mathrm{~min}$ and the supernatants decanted. The remaining residue was then counted for radioactive content. The interassay coefficients of variation for two plasma samples $(2.71 \mathrm{pg} / \mathrm{ml}$ and $5 \cdot 55 \mathrm{pg} / \mathrm{ml} \mathrm{AVP)}$ were $4 \cdot 1$ and $9 \cdot 8 \%$ respectively.

\section{Plasma angiotensin II concentrations}

Plasma angiotensin II concentrations were measured as previously described (Giussani et al. 1996) after chromatographic separation using a sensitive and specific competitive protein-binding RIA with reagents supplied as a kit (Nichols Institute, Diagnostics BV, Saffron Walden, Essex, UK). Plasma samples $(0.5 \mathrm{ml})$ were mixed with

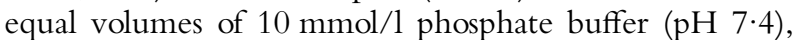
and columns (SepPak $\mathrm{C}_{18}$ ) washed with $10 \mathrm{ml}$ volumes of methanol and phosphate buffer. Samples were then applied to the columns and washed with $10 \mathrm{ml}$ phosphate buffer. Angiotensin II was eluted with $2.5 \mathrm{ml}$ ethanol, and extracts were dried at $37^{\circ} \mathrm{C}$ with a jet of air. Residues were reconstituted in $0.84 \mathrm{ml}$ Tris buffer, and duplicate aliquots $(0.4 \mathrm{ml})$ transferred to polystyrene tubes. A $0.1 \mathrm{ml}$ volume of anti-angiotensin II (rabbit) antiserum was added and samples mixed and incubated at $2-8{ }^{\circ} \mathrm{C}$ for $6 \mathrm{~h}$. Samples were treated with $0 \cdot 1 \mathrm{ml}{ }^{125}$ I-angiotensin II and incubated at $4{ }^{\circ} \mathrm{C}$ for $18 \mathrm{~h}$. Anti-rabbit antiserum (donkey) precipitant $(0.1 \mathrm{ml})$ was added, and tubes were incubated 
at room temperature for $30 \mathrm{~min}$. A $1.0 \mathrm{ml}$ volume of deionized water was added and tubes were centrifuged $(2000 \mathrm{~g})$ for $15 \mathrm{~min}$ at room temperature. The supernatant was then decanted and remaining residue counted for radioactive content. The sensitivity of the assay was $3.8 \mathrm{pg} / \mathrm{ml}$. The intra- and inter-assay coefficients of variation for three plasma samples $(31,42$ and $96 \mathrm{pg} / \mathrm{ml}$ ) were $5 \cdot 1,4 \cdot 0$ and $9 \cdot 3 \%$ respectively.

\section{Plasma catecholamine concentrations}

Epinephrine and norepinephrine were measured by electrochemical detection after HPLC fractionation. Fetal plasma samples $(0.4 \mathrm{ml})$ were spiked with $50 \mu \mathrm{l}$ of the internal standard 6-methyldopamine after microcentrifugation for $1 \mathrm{~min}$ and treated with $400 \mu \mathrm{l} 200 \mathrm{mmol} / \mathrm{l}$ Tris-EDTA. Samples were allowed to equilibrate for $5 \mathrm{~min}$ and then subjected to solid-phase extraction using $3.0 \mathrm{ml} 200 \mathrm{mg}$ Alumina A mini-columns (J \& W Scientific Inc., Folsom, CA, USA) to adsorb all catecholamines. Columns were washed four times with $4 \mathrm{mmol} / 1$ TrisEDTA at $\mathrm{pH} 8.5$, and catecholamines were eluted with $2 \cdot 0 \mathrm{ml}$ glacial acetic acid at $\mathrm{pH} 3 \cdot 0$. Extracts were dried using a Speedvac Concentrator (Savant) and the residue reconstituted in $150 \mu \mathrm{l}$ HPLC eluent and subjected to reverse-phase HPLC on a Bondapak column $(30 \times 0.39 \mathrm{~cm}$; Waters, Mississauga, Ontario, Canada). Catecholamines were eluted with buffer consisting of $50 \mathrm{mmol} / 1$ sodium acetate, $20 \mathrm{mmol} / 1$ citric acid, $0.135 \mathrm{mmol} / 1$ sodium EDTA, $1.0 \mathrm{mmol} / 1 \mathrm{di}-n$-butylamine in water/methanol $(95: 5, \mathrm{v} / \mathrm{v}$ ) at $\mathrm{pH} 4.3$ (containing $3.75 \mathrm{mmol} / 1$ sodium-1-octanesulphonate as an ion-pairing reagent) at a flow rate of $1.0 \mathrm{ml} / \mathrm{min}$. The column eluent was monitored with a model M460 electrochemical detector (Waters) in the oxidative mode at a potential difference of $0.6 \mathrm{~V}$. The peaks were quantified with a model M740 data module (Waters) and compared with those of authentic reference standards of epinephrine, norepinephrine and 6-methyldopamine.

\section{Statistical analyses}

All results are presented as mean values \pm s.E.M. Statistical significance was determined using a two-way ANOVA with repeated measures (BMDP $5 \mathrm{~V}$; BMDP Statistical Software Inc., Los Angeles, CA, USA) comparing the effect of time and group. If a significant effect of time or group was found $(P<0 \cdot 05)$, within-animal comparisons were conducted using Dunnet's post-hoc test (BMDP 7D) and between-group comparisons were made using Student's unpaired $t$-test.

\section{Results}

\section{Blood gases and arterial oxygen saturation}

During the normoxic control period, fetal blood gases and $\mathrm{SaO}_{2}$ were similar in both groups. After the onset of
RUBF, $\mathrm{SaO}_{2}$ decreased $(P<0 \cdot 01)$ similarly in intact and denervated fetuses $(62 \cdot 4 \pm 5 \cdot 0$ and $60 \cdot 3 \pm 6 \cdot 1 \%$ to $35 \cdot 4 \pm 2 \cdot 7$ and $28 \cdot 2 \pm 2 \cdot 0 \%$ respectively) whereas arterial $\mathrm{pCO}_{2}$ did not change $(50 \cdot 9 \pm 0 \cdot 8$ and $51 \cdot 3 \pm 1 \cdot 6 \mathrm{mmHg}$ to $51 \cdot 4 \pm 1 \cdot 8$ and $55.9 \pm 3.5 \mathrm{mmHg}$ respectively). Arterial $\mathrm{pH}$ decreased significantly at $1 \mathrm{~h}$ in both intact and denervated fetuses $(7 \cdot 36 \pm 0 \cdot 01$ and $7 \cdot 38 \pm 0 \cdot 01$ to $7 \cdot 28 \pm 0.02$ and $7 \cdot 25 \pm 0.02$ respectively) as a result of a transient decrease in base excess followed by a return towards control values at $12 \mathrm{~h}$. At 20 and $24 \mathrm{~h}$, arterial $\mathrm{pH}$ was significantly lower $(7 \cdot 26 \pm 0.03$ and $7 \cdot 27 \pm 0.05$ respectively; $P<0.05)$ in denervated fetuses when compared with the normoxia period, although not significantly different from intact fetuses.

\section{Plasma AVP concentrations}

Under normoxic conditions, fetal plasma AVP concentrations were similar in intact and denervated animals. After the onset of RUBF, plasma AVP concentrations increased significantly $(P<0 \cdot 01)$ in intact fetuses from $10 \cdot 0 \pm 1 \cdot 4 \mathrm{pg} / \mathrm{ml}$ to a maximum value of $127 \cdot 3 \pm$ $28.4 \mathrm{pg} / \mathrm{ml}$ at $6 \mathrm{~h}$ and this was followed by a return to normoxic values (Fig. 1). In denervated fetuses, the AVP response was markedly attenuated, increasing from $15.6 \pm 3.6 \mathrm{pg} / \mathrm{ml}$ to a maximum value of only $34.9 \pm$ $6.0 \mathrm{pg} / \mathrm{ml}(P<0 \cdot 05)$ at $6 \mathrm{~h}$ followed by a return to normoxic values.

\section{Plasma angiotensin II concentrations}

Under normoxic conditions, plasma angiotensin II concentrations were similar in intact and denervated fetuses. Plasma angiotensin II concentrations did not change in intact fetuses with the onset of RUBF whereas denervated fetuses demonstrated a marked increase from $47 \cdot 5 \pm 18 \cdot 9 \mathrm{pg} / \mathrm{ml}$ to a maximum value of $128 \cdot 7 \pm 34 \cdot 2 \mathrm{pg} / \mathrm{ml}$ at $12 \mathrm{~h}$, followed by a return to normoxic values (Fig. 2). Plasma angiotensin II concentrations were significantly greater $(P<0 \cdot 05)$ in denervated fetuses at 3, 6 and $12 \mathrm{~h}$ of RUBF when compared with intact fetuses.

\section{Plasma catecholamine concentrations}

Under normoxic conditions, plasma norepinephrine and epinephrine concentrations were similar in intact and denervated fetuses. With the onset of RUBF, plasma norepinephrine concentrations increased in intact fetuses from $1558 \cdot 3 \pm 384 \cdot 4 \mathrm{pg} / \mathrm{ml}$ to a maximum value of $3289 \cdot 2 \pm 1219 \cdot 8 \mathrm{pg} / \mathrm{ml}$ at $12 \mathrm{~h}$, although this was not statistically significant, and remained elevated throughout the $24 \mathrm{~h}$ RUBF period (Fig. 3A). In contrast, denervated fetuses demonstrated no change in plasma norepinephrine concentrations. Plasma epinephrine concentrations demonstrated a modest non-significant increase in intact 


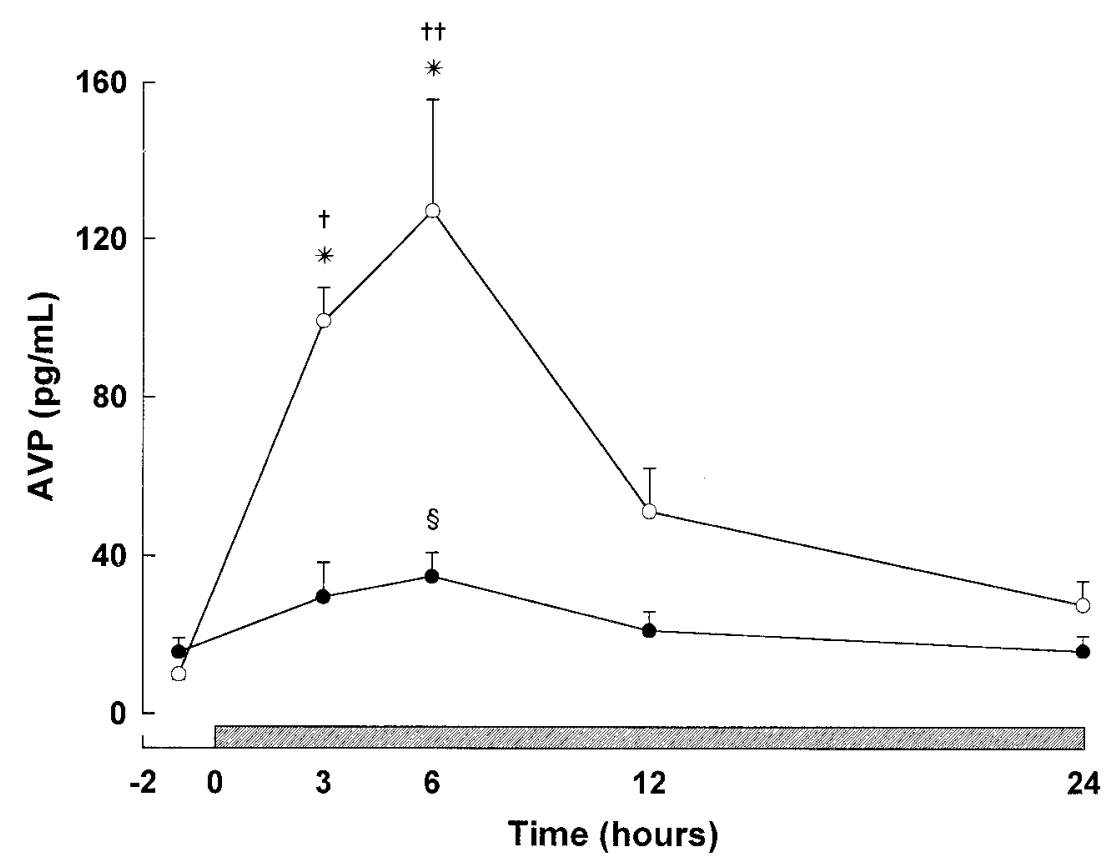

Figure 1 Plasma AVP concentrations measured at selected intervals before and during the $24 \mathrm{~h}$ RUBF period in intact $(\bigcirc)$ and denervated $(\bullet)$ fetuses. Values are means \pm S.E.M. ${ }^{\star} P<0 \cdot 01, \S P<0 \cdot 05$, values significantly different from pre-RUBF values. $\dagger P<0 \cdot 05,+\dagger P<0 \cdot 01$, values significantly different from those for denervated fetuses. Bar represents period of RUBF.

fetuses from $547 \cdot 3 \pm 304 \cdot 7 \mathrm{pg} / \mathrm{ml}$ to a maximum value of $896 \cdot 8 \pm 467 \cdot 8 \mathrm{pg} / \mathrm{ml}$ at $6 \mathrm{~h}$, whereas denervated fetuses demonstrated no change (Fig. 3B).

\section{Discussion}

In the present study we have shown that the AVP and catecholamine responses to prolonged RUBF are markedly attenuated following peripheral chemodenervation. In addition, plasma angiotensin II concentrations increase in denervated fetuses in response to prolonged RUBF whereas intact fetuses demonstrate no change. We propose that alterations in the release of vasoactive hormones in denervated fetuses are responsible in part for the altered cardiovascular responses to prolonged RUBF observed in these animals (Stein et al. 1997).

AVP is known to be an important mediator of fetal cardiovascular responses to acute hypoxia. AVP administration to normoxic fetuses leads to cardiovascular changes similar to those observed with acute hypoxia including a transient bradycardia and hypertension (Rurak 1978, Iwamoto et al. 1979, Tomita et al. 1985). Furthermore, fetal plasma AVP concentrations increase with the onset of acute hypoxia (Rurak 1978, Daniel et al. 1983, Raff et al. 1991), and administration of a $V_{1}$ receptor antagonist partially reverses the associated cardiovascular responses (Perez et al. 1989). The role of the peripheral chemoreceptors in mediating the AVP response to acute hypoxia remains controversial. Bilateral sectioning of the cervical vagosympathetic trunk attenuates the response (Rurak 1978), whereas sinoaortic (Raff et al. 1991) or carotid sinus (Giussani et al. 1994) denervation does not. During prolonged RUBF, fetal plasma AVP concentrations increase to maximum values at $2 \mathrm{~h}$ and return to normoxic values after $12 \mathrm{~h}$ (Hooper et al. 1990), suggesting a transient role in modulating fetal cardiovascular responses. The current study is unique in that it examines for the first time the role of the peripheral chemoreceptors in mediating the fetal AVP response to prolonged hypoxia. In sectioning the carotid sinus and vagus nerves, afferent fibres from sensory receptors other than the carotid and aortic chemoreceptors are removed. It is therefore possible that vagal afferents, including those of low-pressure baroreceptors in the atrium, stimulate the AVP response.

Fetal plasma AVP concentrations increase in response to other stimuli including elevated plasma osmolality and adenosine concentrations (Kelly et al. 1983, Ross et al. 1992). A direct measure of plasma osmolality was not available in the current study, although fetal hematocrit did not change throughout the RUBF period and was similar in both groups. Adenosine, a metabolic product of oxygen deficiency, also increases with acute hypoxia (Koos \& Doany 1991). Adenosine infusion increases plasma AVP 


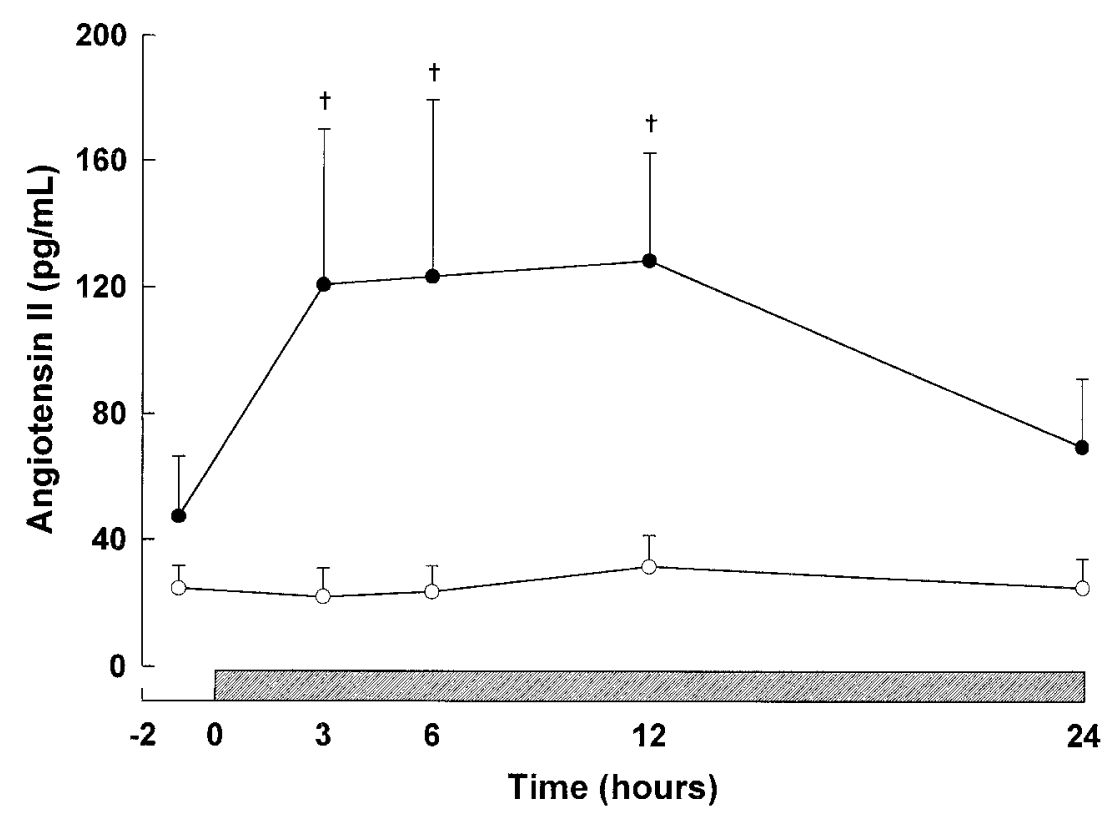

Figure 2 Plasma angiotensin II concentrations measured at selected intervals before and during the $24 \mathrm{~h}$ RUBF period in intact $(\bigcirc)$ and denervated $(\bullet)$ fetuses. Values are means \pm S.E.M. $\dagger P<0 \cdot 05$, values significantly different from those for intact fetuses. Bar represents period of RUBF.

concentrations in fetal sheep whereas infusion of an adenosine receptor antagonist attenuates the rise in plasma AVP concentrations during acute hypoxia (Koos et al. 1994). It would thus be of interest to determine the effect of peripheral chemodenervation on fetal adenosine concentrations during prolonged RUBF.

The sustained tachycardia observed in intact fetuses with prolonged RUBF has previously been demonstrated in our laboratory (Bocking et al. 1988) and is thought to be secondary to $\beta$-adrenergic stimulation associated with a sustained elevation in plasma catecholamine concentrations (Hooper et al. 1990, Bocking et al. 1995). Jensen \& Hanson (1995) reported that the increase in catecholamine levels associated with acute fetal asphyxia is delayed following carotid chemodenervation, suggesting that sympathetically mediated catecholamine release is in part a carotid chemoreflex. The lower circulating catecholamine levels observed in denervated fetuses in the present study would support an additional role for the peripheral chemoreceptors in mediating adrenomedullary catecholamine release under conditions of prolonged RUBF.

The lower circulating catecholamine levels observed in denervated fetuses may reflect changes in the neural control of catecholamine release mediated through sympathetic efferent innervation of the adrenal gland. Alternatively, changes in adrenal blood flow related to both splanchnic nerve activity and changes in local factors affecting adrenomedullary capillary dilatation may account for this decrease. Fetal adrenal blood flow in both the medullary and cortical regions decreases in response to acute hypoxia following splanchnicotomy (Buchwalder et al. 1996). Furthermore, a study in adult dogs has demonstrated an increase in adrenal medullary blood flow in response to splanchnic nerve stimulation (Breslow et al. 1993). After administration of the nitric oxide (NO) synthase inhibitor L-NAME, however, splanchnic nerve stimulation no longer had an effect on medullary blood flow, suggesting that the increase is mediated through increased NO levels. It would be of interest to determine the role of NO in mediating adrenal blood flow changes in the fetus in response to both acute and prolonged hypoxia.

The fetal renin-angiotensin system responds to various stimuli, including acute hypoxia, with increases in both plasma renin activity and angiotensin II concentrations (Broughton Pipkin et al. 1974, Robillard et al. 1981, 1984, Tomita et al. 1985). Angiotensin II administration to normoxic fetuses alters heart rate and blood flow through selected vascular beds, and increases arterial blood pressure (Lumbers \& Reid 1978, Iwamoto \& Rudolph 1981). Green et al. (1997) have demonstrated, however, that fetal cardiovascular responses to acute hypoxia are not dependent on angiotensin II. In contrast, angiotensin II does appear to modulate arterial blood pressure and femoral vascular tone during acute hypoxia following carotid sinus denervation, as captopril infusion attenuates the rise in arterial pressure and femoral vascular resistance under these conditions (Green et al. 1997). In the current study, plasma angiotensin II concentrations did not change in 

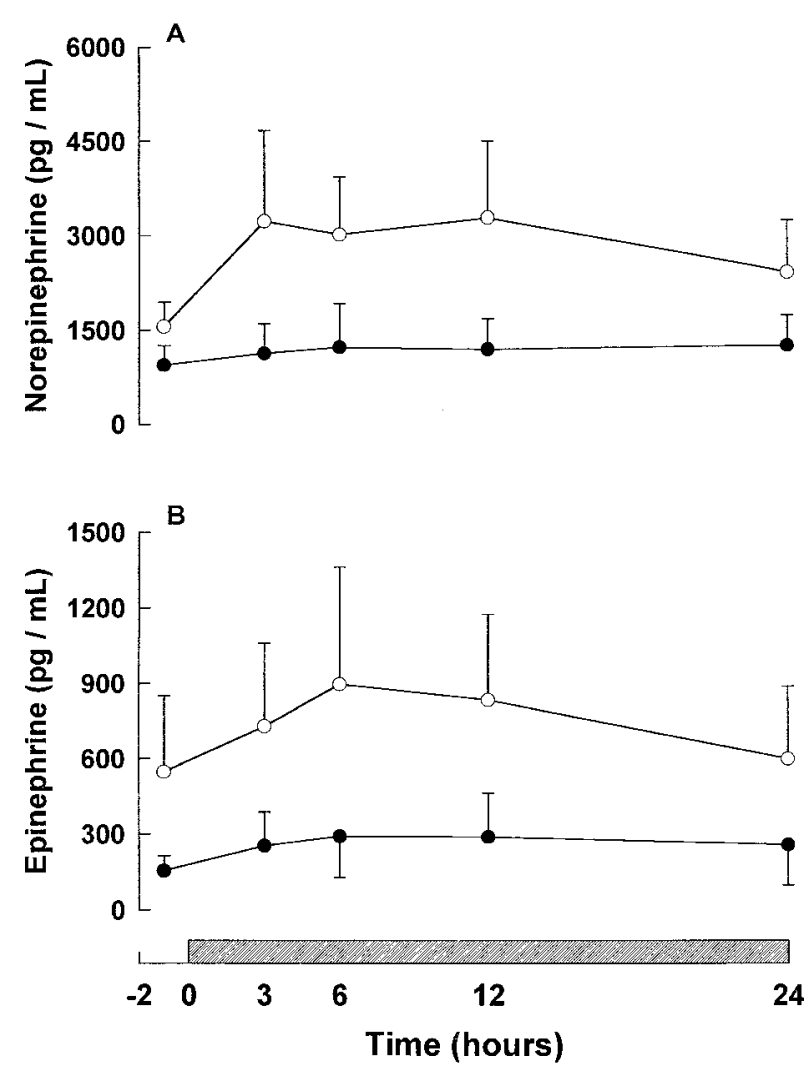

Figure 3 Plasma norepinephrine (A) and epinephrine (B) concentrations measured at selected intervals before and during the $24 \mathrm{~h}$ RUBF period in intact $(\bigcirc)$ and denervated $(\mathbf{O})$ fetuses. Values are means \pm S.E.M. Bar represents period of RUBF.

intact fetuses throughout the $24 \mathrm{~h}$ RUBF period, suggesting that angiotensin II does not normally mediate cardiovascular responses to prolonged hypoxia. It is of note, however, that the first measurement of angiotensin II in the present study, under RUBF conditions, was at $3 \mathrm{~h}$. We therefore cannot exclude a possible earlier rise in plasma angiotensin II concentrations in intact fetuses. In denervated fetuses, however, the angiotensin II response to prolonged RUBF was markedly different, increasing to values significantly greater than in intact fetuses by $3 \mathrm{~h}$ and returning to normoxic values by $24 \mathrm{~h}$. These observations are consistent with the proposed role for angiotensin II in regulating fetal cardiovascular responses to hypoxia once peripheral chemoreflex mechanisms are removed (Green et al. 1997).

The rise in plasma angiotensin II concentrations in denervated fetuses may also occur in response to the sustained hypotension observed in these animals. A decrease in arterial blood pressure stimulates renin secretion via intra- and extra-renal baroreceptor mechanisms, subsequently increasing plasma angiotensin II concentrations. Alternatively, peripheral chemodenervation may have affected angiotensin II clearance which occurs largely in the fetal placental vascular bed (Lumbers \& Reid 1978, Rosenfeld et al. 1995). Placental blood flow is significantly reduced during acute hypoxia in both vagotomized and sinoaortic denervated fetuses (Jansen et al. 1989) and it is therefore possible that reduced placental blood flow in peripheral chemodenervated fetuses caused a decrease in angiotensin II clearance with prolonged RUBF.

In summary, we have shown for the first time that increases in plasma AVP and catecholamine concentrations during prolonged RUBF are attenuated following peripheral chemodenervation in fetal sheep. These alterations in the AVP and catecholamine responses to prolonged RUBF may account for the altered cardiovascular responses observed in denervated fetuses. In addition, fetal plasma angiotensin II concentrations increase during prolonged RUBF following bilateral sectioning of the carotid sinus and vagus nerves, providing evidence that angiotensin II plays a secondary compensatory role in mediating fetal cardiovascular responses to prolonged RUBF once peripheral chemoreceptor mechanisms are removed.

\section{Acknowledgements}

This work was supported by the Medical Research Council of Canada and The Wellcome Trust.

\section{References}

Bocking AD, Gagnon R, White SE, Homan J, Milne KM \& Richardson BS 1988 Circulatory responses to prolonged hypoxemia in fetal sheep. American Journal of Obstetrics and Gynecology 159 $1418-1424$

Bocking AD, White SE, Kent S, Fraher L, Han VKM, Rundle H \& Hooper SB 1995 Effect of prolonged catecholamine infusion on heart rate, blood pressure, breathing, and growth in fetal sheep. Canadian Journal of Physiology and Pharmacology 73 1750-1758.

Breslow MJ, Tobin JR, Bredt DS, Ferris CD, Snyder SH \& Traystman RJ 1993 Nitric oxide as a regulator of adrenal blood flow. American Journal of Physiology 246 H464-H469.

Broughton Pipkin F, Lumbers ER \& Mott JC 1974 Factors influencing plasma renin and angiotensin II in the conscious pregnant ewe and its foetus. Journal of Physiology 243 619-636.

Buchwalder L, Lin M, Unno N, Nathanielsz PW \& McDonald TJ 1996 Splanchnicotomy reduces fetal adrenal blood flow response to hypoxemia in sheep. Journal of the Society for Gynecological Investigation 3 258A.

Daniel SS, Stark RI, Zubrow AB, Fox HE, Husain MK \& James LS 1983 Factors in the release of vasopressin by the hypoxic fetus. Endocrinology 113 1623-1628.

Giussani DA, McGarrigle HHG, Spencer JAD, Moore PJ, Bennet L \& Hanson MA 1994 Effect of carotid denervation on plasma vasopressin levels during acute hypoxia in the late-gestation sheep fetus. Journal of Physiology 477 81-87.

Giussani DA, Riquelme RA, Moraga FA, McGarrigle HH, Gaete CR, Sanhueza EM, Hanson MA \& Llanos AJ 1996 Chemoreflex and endocrine components of cardiovascular responses to acute hypoxemia in the llama fetus. American Journal of Physiology 271 R73-R83.

Green LR, McGarrigle HHG, Bennet L \& Hanson MA 1997 Angiotensin II and cardiovascular chemoreflex responses to 
acute hypoxia in late gestation fetal sheep. Journal of Physiology (In Press).

Gu W, Jones CT \& Parer JT 1985 Metabolic and cardiovascular effects on fetal sheep of sustained reduction of uterine blood flow. Journal of Physiology 368 109-129.

Hooper SB, Coulter CL, Deayton JM, Harding R \& Thorburn GD 1990 Fetal endocrine responses to prolonged hypoxemia in sheep. American Journal of Physiology 259 R703-R708.

Iwamoto HS \& Rudolph AM 1981 Effects of angiotensin II on the blood flow and its distribution in fetal lambs. Circulation Research $\mathbf{4 8}$ 183-189.

Iwamoto HS, Rudolph AM, Keil LC \& Heymann MA 1979 Hemodynamic responses of the sheep fetus to vasopressin infusion. Circulation Research 44 430-436.

Jansen AH, Belik J, Ioffe S \& Chernick V 1989 Control of organ blood flow in fetal sheep during normoxia and hypoxia. American Journal of Physiology 257 H1132-H1139.

Jensen A \& Hanson MA 1995 Circulatory responses to acute asphyxia in intact and chemodenervated fetal sheep near term. Reproduction, Fertility and Development 7 1351-1359.

Jones CT \& Robinson RO 1975 Plasma catecholamines in foetal and adult sheep. Journal of Physiology 248 15-33.

Kelly RT, Rose JC, Meis PJ, Hargrave BY \& Morris M 1983 Vasopressin is important for restoring cardiovascular homeostasis in fetal lambs subjected to hemorrhage. American Journal of Obstetrics and Gynecology 146 807-812.

Koos BJ \& Doany W 1991 Role of plasma adenosine in breathing responses to hypoxia in fetal sheep. Journal of Developmental Physiology 16 81-85.

Koos BJ, Mason BA \& Ervin MG 1994 Adenosine mediates hypoxic release of arginine vasopressin in fetal sheep. American Journal of Physiology 266 R215-R220.

Lumbers ER \& Reid GC 1978 The actions of vasoactive compounds in the foetus and the effect of perfusion through the placenta on their biological activity. Australian Journal of Experimental Biology and Medical Science 56 11-24.

Perez R, Espinoza M, Riquelme R, Parer JT \& Llanos AJ 1989 Arginine vasopressin mediates cardiovascular responses to hypoxemia in fetal sheep. American Journal of Physiology 256 R1011-R1018.

Raff H, Curtis WK \& Wood CE 1991 Arginine vasopressin responses to hypoxia and hypercapnia in late-gestation fetal sheep. American Journal of Physiology 260 R1077-R1081.

Robillard JE, Weitzman RE, Burmeister L \& Smith FG 1981 Developmental aspects of the renal response to hypoxemia in the lamb fetus. Circulation Research 48 128-138.

Robillard JE, Ayres NA, Gomez GA, Nakamura KT \& Smith FG 1984 Factors controlling aldosterone secretion during hypoxemia in fetal lambs. Pediatric Research 18 607-611.

Rosenfeld CR, Gresores A, Roy TA \& Magness RR 1995 Comparison of ANG II in fetal and pregnant sheep: metabolic clearance and vascular sensitivity. American Journal of Physiology 268 E237-E247.

Ross MG, Agnew C, Fujino Y, Ervin MG \& Day L 1992 Concentration thresholds for fetal swallowing and vasopressin secretion. American Journal of Physiology 262 R1057-R1063.

Rurak DW 1978 Plasma vasopressin levels during hypoxaemia and the cardiovascular effects of exogenous vasopressin in foetal and adult sheep. Journal of Physiology 277 341-357.

Stein P, White SE, Homan J, Fraher L, Hanson MA \& Bocking AD 1997 Cardiovascular responses to prolonged reduced uterine blood flow are mediated by the peripheral chemoreceptors in fetal sheep. Journal of the Society for Gynecological Investigation $\mathbf{4}$ $81 \mathrm{~A}$.

Tomita H, Brace RA, Cheung CY \& Longo LD 1985 Vasopressin dose-response effects on fetal vascular pressures, heart rate, and blood volume. American Journal of Physiology 249 H974-H980.

Wood CE, Kane C \& Raff H 1990 Peripheral chemoreceptor control of fetal renin responses to hypoxia and hypercapnia. Circulation Research 67 722-732.

Received 5 August 1997

Revised manuscript received 3 November 1997 Accepted 10 November 1997 